\title{
Dryocrassin ABBA Induces Apoptosis in Human Hepatocellular Carcinoma HepG2 Cells Through a Caspase-Dependent Mitochondrial Pathway
}

\author{
Zhe Jin, Wen-Fei Wang, Jian-Ping Huang, He-Meng Wang, Han-Xun Ju, Ying Chang*
}

\begin{abstract}
Background: Biological and pharmacological activities of dryocrassin ABBA, a phloroglucinol derivative extracted from Dryopteris crassirhizoma, have attracted attention. In this study, the apoptotic effect of dryocrassin ABBA on human hepatocellular carcinoma HepG2 cells was investigated. Materials and Methods: We tested the effects of dryocrassin ABBA on HepG2 in vitro by MTT, flow cytometry, real-time PCR, and Western blotting. KM male mice were used to detect the effect of dryocrassin ABBA on $\mathrm{H22}$ cells in vivo. Results: Dryocrassin ABBA inhibited the growth of HepG2 cells in a concentration-dependent manner. After treatment with 25, 50, and $75 \mu \mathrm{g} / \mathrm{mL}$ dryocrassin ABBA, the cell viability was $68 \%, 60 \%$ and $49 \%$, respectively. Dryocrassin ABBA was able to induce apoptosis, measured by propidium iodide (PI)/annexin V-FITC double staining. The results of real-time PCR and Western ting showed that dryocrassin ABBA up-regulated p53 and Bax expression and inhibited Bcl-2 expression which led to an activation of caspase-3 and caspase-7 in the cytosol, and then induction of cell apoptosis. In vivo experiments also showed that dryocrassin ABBA treatment significantly suppressed tumor growth, without major side effects. Conclusions: Overall, these findings provide evidence that dryocrassin ABBA may induce apoptosis in human hepatocellular carcinoma cells through a caspase-mediated mitochondrial pathway.
\end{abstract}

Keywords: Dryocrassin ABBA - HepG2 - apoptosis - mitochondrial pathway - H22 tumors

Asian Pac J Cancer Prev, 16 (4), 1823-1828

\section{Introduction}

Hepatocellular carcinoma is the most common and one of the highest degree of malignancy of the tumor. It has the fifth highest incidence rate in the world, and its mortality rates ranked the third (Parkin, 2001). Currently, most chemotherapeutic agents in clinical use currently are effective in combating cancer cells, but they also induce various adverse effects (Roy et al., 2005). Chemotherapeutic agents, such as paclitaxel and anthracyclines, cause severe side effects and drug resistance in patients (Fauzi et al., 2011). In recent years, antitumour drugs from plants have drawn attention because of their strong effects and low toxicities. Thus, developing natural therapeutic agents to treat hepatocellular carcinoma is necessary.

Ferns are known to be rich in natural compounds, containing phloroglucinol derivatives, flavonoid and polysaccharide etc. Among these natural compounds, the content of phloroglucinol is highest. Total phloroglucinol extract from Dryopteris crassirhizoma has significant anticancer activity to multiple transplanted animal tumor. Dryocrassine ABBA is phloroglucinol derivative extracted from Dryopteris crassirhizoma. Dryocrassine ABBA exhibits potential application in treating ARS ascites tumor, U14 cervical cancer, Lewis lung cancer (Guo, 1992). The chemical structure of Dryocrassine ABBA is shown in Figure 1.

Induction of apoptosis is very effective for treating cancers. Data indicate that, for most of commonly-used anticancer agents, activation of apoptotic pathways to kill cancer cells is a dominant anticancer mechanism (Lau et al., 2008). Many anticancer drugs cause tumor cells apoptosis through two major routes, the death receptor pathway characterized by activation of cell-surface death receptors and the mitochondrial pathway depending on the release of mitochondrial factors (Kuo et al., 2008). The integrity of the mitochondrial membrane can be regulated by Bcl-2 family proteins which consist of anti-apoptotic and pro-apoptotic factors (Perfettini et al., 2002). For the mitochondrial pathway, decrease in the ratio of Bcl-2/Bax in mitochondria can result in release of mitochondrial factors, triggering caspase cascades leading to apoptosis (Zhou et al., 2009). Quercetin, for example induces apoptosis via caspase activation and regulation of $\mathrm{Bcl}-2$ in a human hepatoma cell line (HepG2) (Granado et al., 2006).

This study was to explore the potential anticancer 
activity of Dryocrassin ABBA towards human HepG2 cells for the first time. Our results suggested that Dryocrassin ABBA induced apoptosis of HepG2 cells through a caspase- 3 and caspase- 7 dependent mitochondrial pathway, involving p53 and $\mathrm{Bcl} 2$ family protein expression. In vivo experiments showed that Dryocrassin ABBA could promote apoptosis in a dosagedependent manner in $\mathrm{H} 22$ tumor in mice. This is the first study investigating the anticancer activity and underlying mechanisms of Dryocrassin ABBA in HepG2 cells, providing promising evidence for clinical application of Dryocrassin ABBA in human hepatocarcinoma treatment.

\section{Materials and Methods}

\section{Cell culture and Dryocrassin ABBA treatment}

Human hepatocellular carcinoma HepG2 cells were maintained in RPMI-1640 supplemented with $10 \%$ fetal calf serum and antibiotics $(100 \mathrm{U} / \mathrm{mL}$ penicillin and 100 $\mu \mathrm{g} / \mathrm{mL}$ streptomycin) at $37^{\circ} \mathrm{C}$ in a humidified atmosphere of 5\% CO2. Dryocrassin ABBA ( purity 98\%, Forever Biotechnology, Shanghai, China) was dissolved in $15 \%$ ethanol to make a $100 \mu \mathrm{g} / \mathrm{mL}$ stock solution and stored at $-20^{\circ} \mathrm{C}$. Stock solution was further diluted to final concentrations of 25,50 and $75 \mu \mathrm{g} / \mathrm{mL}$ with serumfree culture medium. Cells with $15 \%$ ethanol treatment (without Dryocrassin ABBA) served as control group.

\section{Cell proliferation assays}

Inhibition of cell proliferation by Dryocrassin ABBA was measured by the MTT assay (Liu et al., 2009). HepG2 cells were plated in 96 -well culture plates $\left(1 \times 10^{5}\right.$ cells/ well), incubated overnight. Afterwards, the cells were treated with the indicated concentrations of Dryocrassin ABBA for $48 \mathrm{~h}$. Followed by incubation with $0.5 \mathrm{mg} / \mathrm{mL}$ MTT for $4 \mathrm{~h}$. Then the medium was removed. Finally, $100 \mu \mathrm{L}$ of DMSO was added to each well to dissolve the formazan crystals. Absorbance at $570 \mathrm{~nm}$ was measured with a microtiter plate reader (Sunrise Remote/Touch screen, Colum-busplus, Austria). The following formula was used for the cell viability ratio calculation:

Cell viability ratio $100 \%=(\mathrm{OD}$ treated $/ O D$ control) $\times 100 \%$

\section{Annexin Vassay for apoptosis}

Apoptotic cells were identified by AnnexinVFITC Apoptosis Detection Kits (Beyotime Institute of Biotechnology, China). Cells undergoing apoptosis were identified by binding of Annexin $\mathrm{V}$ protein to exposed phosphatidylserine (PS) residues at cell surface (Jiang et al., 2008). After exposure to Dryocrassin ABBA (0, 25, 50 and $75 \mu \mathrm{g} / \mathrm{mL}$ ) for $48 \mathrm{~h}$, cells were collected, washed twice with PBS, gently resuspended in annexinV-binding buffer, and incubated with annexinV-FITC and PI in dark for 10 min. FITC fluorescence was analyzed by flow Cytometry (Partec Flow cytometry, PAS, Germany).

\section{Quantitative RT-PCR}

HepG2 cells were treated with Dryocrassin ABBA $(0,25,50$ and $75 \mu \mathrm{g} / \mathrm{mL})$ for $48 \mathrm{~h}$. Then the medium was removed. Total RNA was extracted with TRIzol reagent according to the manufacturer's instructions. Spectrophotometry was then performed to measure the concentration of each total RNA sample. Using the reverse transcription-polymerase chain reaction (RT-PCR) portion of the Haiene reverse transcription kit, first-strand cDNA was synthesized by RT to transcribe poly (A)+ mRNA with oligo-dT primers following the manufacturer's instructions. The gene expression level of $\beta$-actin, Bax, Bcl-2, P53, Fas, Caspase-3 and Caspase-7 was analyzed using a real-time PCR detection system (LineGene 9620, Hangzhou Bioer Technology Co., LTD, HangZhou, China). The primers used was shown in Table 1.

$\beta$-actin was used as an internal reference. Quantitative real-time PCR (qRT-PCR) experiments were performed in triplicate. The results were analyzed using the 2- $\Delta \Delta \mathrm{CT}$ method (Livak et al., 2001).

\section{Western blot assay}

Cytosolic fraction was diluted with lysis buffer and incubated with SDS-PAGE loading buffer at $95^{\circ} \mathrm{C}$ for 5 min. Equal amounts of protein were loaded on $10 \%$ SDSpolyacrylamide gels and transferred onto polyvinylidene fluoride membranes (PVDF). Membranes were blocked with $5 \%$ nonfat milk for $2 \mathrm{~h}$ at room temperature

and incubated overnight at $4^{\circ} \mathrm{C}$ with primary antibodies ( $\mathrm{Bax}, \mathrm{Bcl}-2, \beta$-actin ). Horseradish peroxidase conjugated anti-mouse IgG was used as the secondary antibody. Finally, proteins were detected with ECL reagent.

\section{In vivo anti-tumor activity}

$\mathrm{H} 22$ cells $\left(2 \times 10^{5}\right)$ were subcutaneously injected into the right flank of 5-week-old KM male mice. Groups of four mice were used and randomly divided. Ten days after inoculation, the diameters of the tumors reached 3 to $5 \mathrm{~mm}$. Then three groups were subcutaneously injected with different concentrations of Dryocrassin ABBA (0, 25,50 and $75 \mu \mathrm{g} / \mathrm{mL}$ ) $0.7 \mathrm{mg} / \mathrm{kg} / \mathrm{d}$. When the diameters of the tumors reached $13 \mathrm{~mm}$, the mice were euthanized, and the tumor tissues were segregated and fixed by paraformaldehyde for observation of pathomorphology.

\section{Statistics}

All data were expressed as the mean \pm SD of three replicates. Significant differences between groups were analyzed by one-way factorial analysis of variance

\section{Table 1. Primers and Real-Time PCR Conditions}

\begin{tabular}{|c|c|c|c|}
\hline Target gene & $\begin{array}{c}\text { Anneal } \\
\text { temperature }(\end{array}$ & & $\begin{array}{l}\text { Product } \\
\text { (bp) }\end{array}$ \\
\hline$\beta$-actin & $\begin{array}{l}\text { 5'-GGGAAATCGTGCGTGAC-3' } \\
\text { 5'-TTGCCAATGGTGATGACCTG-3' }\end{array}$ & 62 & 139 \\
\hline Bax & $\begin{array}{l}\text { 5'-ATGCGTCCACCAAGAAGCTGAG-3' } \\
\text { 5'- CCCCAGTTGAAGTTGCCGTCAG -3', }\end{array}$ & 61 & 162 \\
\hline Bcl-2 & $\begin{array}{l}\text { 5'-GAGGATTGTGGCCTTCTTTG-3' } \\
\text { 5'-ACAGTTCCACAAAGGCATCC-3', }\end{array}$ & 55.5 & $\begin{array}{ll}5 & 177\end{array}$ \\
\hline P53 & $\begin{array}{l}\text { 5'-CCACCATCCACTACAACTACAT-3' } \\
\text { 5'-CAAACACGGACAGGACCC-3' }\end{array}$ & 52 & 149 \\
\hline Fas & $\begin{array}{l}\text { 5'-CTCCAAGGGATTGGAATTGA-3' } \\
\text { 5'-GACAAAGCCACCCCAAGTTA-3', }\end{array}$ & 54 & 443 \\
\hline Caspase-3 & $\begin{array}{l}\text { 5'-ATGGAAGCGAATCAATGGAC-3' } \\
\text { 5'-ATCACGCATCAATTCCACAA-3' }\end{array}$ & 53 & 242 \\
\hline Caspase-7 & $\begin{array}{l}\text { 5'- GCGAACTAACAGGCAAGCA-3' } \\
\text { 5'-CCAAATCCTCCAGAACCAAT-3' }\end{array}$ & 54 & 144 \\
\hline
\end{tabular}


Dryocrassin ABBA Induces Apoptosis in Human HepG2 Cells Through a Caspase-Dependent Mitochondrial Pathway

(ANOVA), followed by Duncan's post hoc test using the SPSS statistical software package version 17.0 (SPSS Inc., Chicago, USA). The results were considered statistically significant at $P<0.05$.

\section{Results}

Dryocrassin ABBA inhibits cell viability in HepG2 cells

The inhibitory effect of Dryocrassin ABBA was evaluated by measurement of the viability of HepG2 cells. The MTT assay was applied to test the antiproliferative effect of Dryocrassin ABBA on HepG2 cells in vitro. Our results showed that Dryocrassin ABBA effectively inhibited the proliferation of HepG2 cells in a dose-dependent manner. As shown in Figure 2, after treatment for $48 \mathrm{~h}$ at concentrations of 25, 50, and $75 \mu \mathrm{g} / \mathrm{mL}$, Dryocrassin ABBA treatment resulted in significant decrease in cell viability by $68 \%, 60 \%$ and $49 \%$, respectively.

Effect of Dryocrassin ABBA on apoptosis in HepG2 cells

To investigate whether the reduction in cell viability was due to apoptosis, cytometric analysis of the cells was performed. We double-stained cells with annexin $\mathrm{V}$ and PI and analyzed the results using flow cytometer. Dryocrassin ABBA led to a concentration-dependent externalization of phosphatidylserine (PS), a mark of the apoptosis. Q2 contained late-apoptotic or necrotic cells. Q3 contained intact cells and Q4 contained early apoptotic cells. After treatment with Dryocrassin ABBA for $48 \mathrm{~h}$, the percentages of both early and late apoptotic cells increased from $1.9 \pm 0.93 \%$ to $19.9 \pm 1.02 \%$ and $4.8 \pm 1.24 \%$ to $73.7 \pm 0.67 \%(p<0.05)$, respectively ( Figure 3$)$. All of which suggests that apoptosis was induced by Dryocrassin ABBA induced apoptosis.

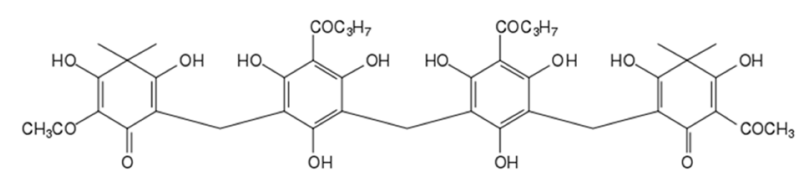

Figure 1. Structures of Dryocrassin ABBA

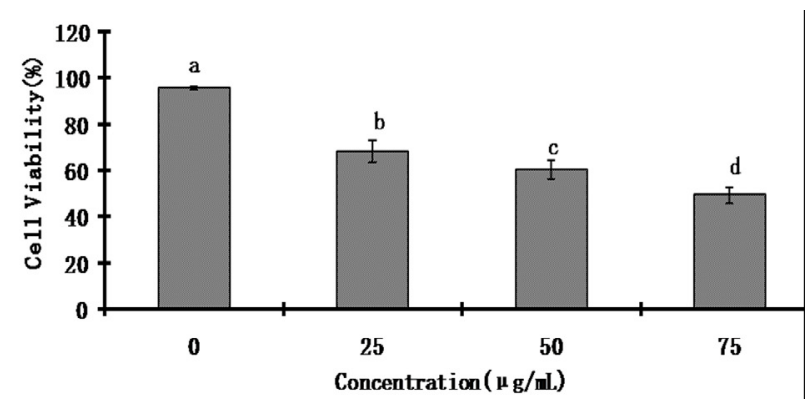

Figure 2. Dryocrassin ABBA Reduces the Viability of HepG2 Cells. The cells were incubated with Dryocrassin ABBA at $0,25,50$, and $75 \mu \mathrm{g} / \mathrm{mL}$ for $48 \mathrm{~h}$. The viable cells were determined using MTT assay. A significant difference between the control group and the Dryocrassin ABBA treatment group was indicated with different lowercase letters $(\mathrm{I}<0.05)$. Each value was expressed as the mean $\pm \mathrm{SD}(\mathrm{n}=3)$

\section{Real-time PCR}

To investigate whether Dryocrassin ABBA altered Bcl-2, Bax, p53, Fas, Caspase-3 and Caspase-7 mRNA expression in HepG2 cells, real-time PCR analysis using gene-specific primers was performed after $24 \mathrm{~h}$ of exposure of HepG2 cells Dryocrassin ABBA $(0,25$, 50 , and $75 \mu \mathrm{g} / \mathrm{mL}$ ). The effect of Dryocrassin ABBAinduced cytotoxicity on the mRNA expression of apoptosis genes are shown in Figure 4. The mRNA levels of Bax, p53, Caspase- 3 , Caspase- 7 in the $75 \mu \mathrm{g} / \mathrm{mL}$ group were significantly higher $(P<0.05)$ than the control group. The mRNA levels of Bcl-2 in the $75 \mu \mathrm{g} / \mathrm{mL}$ group were significantly lower $(P<0.05)$ than the control group. The gene expression level of Fas showed no change after the treatment with Dryocrassin ABBA for 24 h. Bax, p53, Caspase-3 and Caspase-7 were up-regulated, and Bcl-2

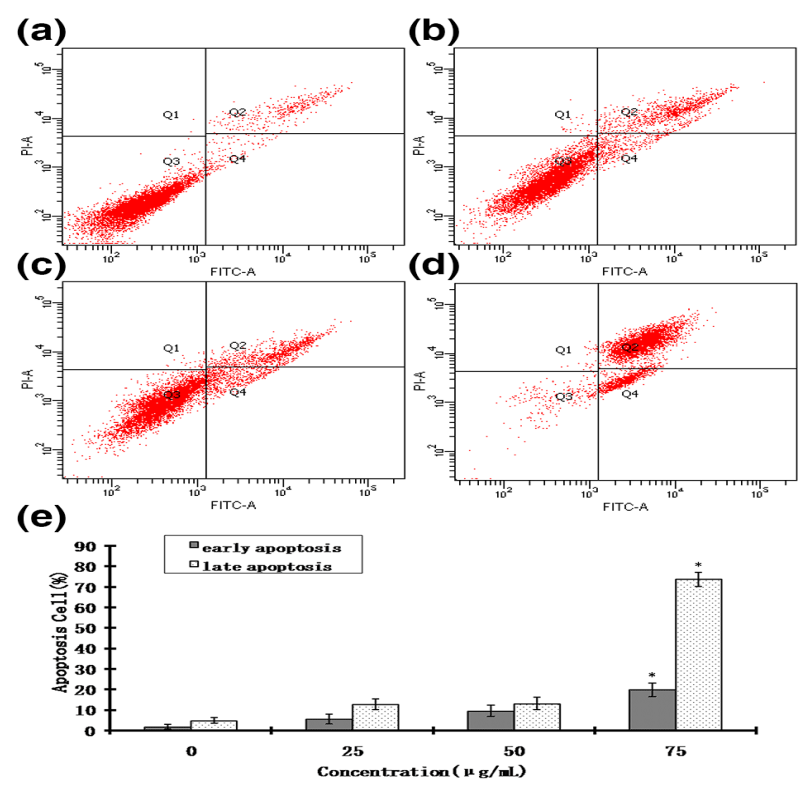

Figure 3. Dryocrassin ABBA-Induced Apoptosis in HepG2 Cells Using AnnexinV-FITC/PI. Flow cytometric histograms. Cells were treated with different concentrations of Dryocrassin ABBA for $48 \mathrm{~h}$. (a) Control; (b) treatment with $25 \mu \mathrm{g} / \mathrm{mL}$ Dryocrassin ABBA; (c) treatment with $50 \mu \mathrm{g} / \mathrm{mL}$ Dryocrassin ABBA; (d) treatment with $75 \mu \mathrm{g} / \mathrm{mL}$ Dryocrassin ABBA; (e) Columns represent mean values $( \pm \mathrm{SD})$ of three experiments $p<0.05$ compared to control ( $0 \mu \mathrm{g} / \mathrm{mL}$ ). The experiments were repeated three times and representative photographs are shown

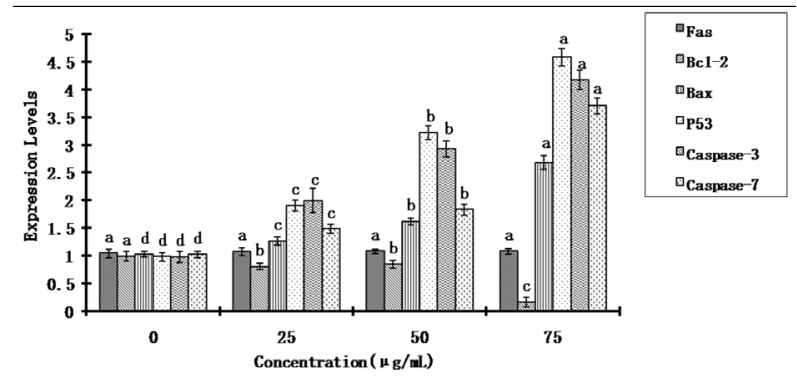

Figure 4. Expression Change of Bax, p53,Fas, Caspase-3 and Caspase-7 Under Different Concentrations of Dryocrassin ABBA Treatment $(0,25,50$ and $75 \mu \mathrm{g} /$ $\mathbf{m L}$ ). A significant difference between the control group and the Dryocrassin ABBA treatment group was indicated with different lowercase letters $(P<0.05)$. Each value was expressed as the mean $\pm \mathrm{SD}(\mathrm{n}=3)$ 
was down-regulated in Dryocrassin ABBA-treated cells compared to control cells. The gene expression level of Fas showed no change. These results show that Dryocrassin ABBA induced apoptosis of HepG2 cells via the alteration of the $\mathrm{Bax} / \mathrm{Bcl}-2$ ratio, involving p53 gene expression. Accompany with activation of caspase- 3 and caspase- 7 .

\section{Effect of Dryocrassin ABBA on the expression of Bax and Bcl-2 proteins}

Apoptosis is regulated by pro-apoptotic and antiapoptotic Bcl-2 protein family members. The upregulation of $\mathrm{Bax}$ and down-regulation of $\mathrm{Bcl}-2$ by Dryocrassin ABBA were further confirmed by protein expression analysis using Western blot (Figure 5). We measured the protein expression of $\mathrm{Bax}$ and $\mathrm{Bcl}-2$ in cells treated with different concentrations of Dryocrassin ABBA for $48 \mathrm{~h}$. Figure 5 shows a significant increase in the levels of Bax, in contrast a notable decrease in Bcl-2 levels.

\section{Dryocrassin ABBA tumor growth suppression}

After the animal tumor modules were successfully established, different concentrations of Dryocrassin ABBA $(0,25,50$ and $75 \mu \mathrm{g} / \mathrm{mL})$ were subcutaneously injected at a dosage of $0.7 \mathrm{mg} / \mathrm{kg} / \mathrm{d}$. In negative control group, tumor cells showed tightly packed, vigorous growth, and abundant cytoplasm; Other groups tumor

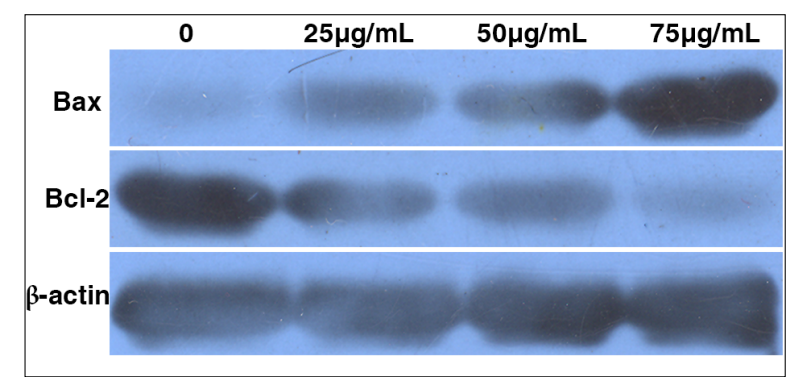

Figure 5. Expression of Apoptosis-Related Proteins in HepG2 Cells after Dryocrassin ABBA treatment for $48 \mathrm{~h}$ as assessed by Western blot analysis. Dryocrassin ABBA-mediated up-regulation of Bax and down regulation of Bcl-2. HepG2 cells were treated with Dryocrassin $\operatorname{ABBA}(0,25$, 50 and $75 \mu \mathrm{g} / \mathrm{mL}$ ) for $48 \mathrm{~h}$, respectively. The tests were repeated three times and representative blots are shown
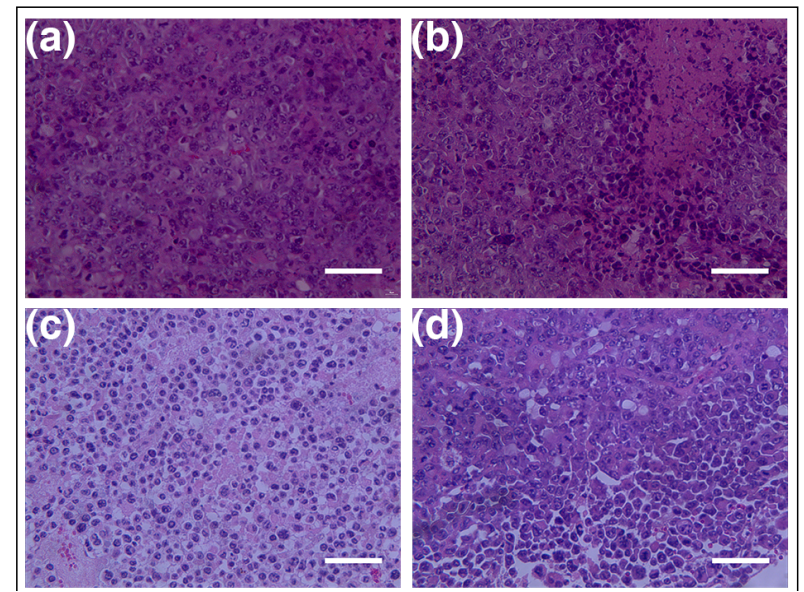

Figure 6. HE Staining Tumor Sections Shows Tumors.

A) Control; B) treatment with $25 \mu \mathrm{g} / \mathrm{mL}$ Dryocrassin ABBA; C) treatment with $50 \mu \mathrm{g} / \mathrm{mL}$ Dryocrassin ABBA; D) treatment with $75 \mu \mathrm{g} / \mathrm{mL}$ Dryocrassin ABBA; the ruler units in this figure is $0.5 \mu \mathrm{m}$ cells were less, arranged loosely with decreased volume, and karyopyknosis and necrotic area were increased. The HE staining results showed that 25,50 or $75 \mu \mathrm{g} / \mathrm{mL}$ Dryocrassin ABBA could effectively induced cell death in tumor cells compared to the control group ( $0 \mu \mathrm{g} / \mathrm{mL})$.

\section{Discussion}

Plant extracts possess considerable potential as anticancer agents due to their effect on inhibiting tumor growth, angiogenesis, and metastasis with few side effects (Nigam et al., 2009). Therefore, natural compounds from medicinal plants have been reported to have anticancer effect (Newman et al., 2003). In recent years researches showed natural compounds extract from plant have effective anti tumor activity. Curdione, one of the major components of Curcuma zedoaria, it Inhibits proliferation of MCF-7 cells by inducing apoptosis (Li et al., 2014). Quercetin is flavonoid compound, inducing apoptosis by direct activation of caspase cascade (mitochondrial pathway) and by inhibiting survival signaling in HepG2 (Zhou et al., 2009). Dryopteris crassirhizoma contains amounts of natural compounds, mainly phloroglucinol derivatives. Dryocrassin ABBA extract from Dryopteris crassirhizoma belongs to phloroglucinol derivatives. Its biological and pharmacological activities lack corresponding attention. It has been reported that Dryocrassine ABBA exhibits potential application in treating ARS ascites tumor, U14 cervical cancer, and Lewis lung cancer (Guo, 1992). However, the mechanism of Dryocrassin ABBA-induced apoptosis has not been reported previously. Preliminary experiments in our laboratory showed that HepG2 cells were sensitive to Dryocrassin ABBA. Therefore, we investigated the anti-proliferative effect and molecular mechanisms of Dryocrassin ABBA on HepG2 cells in more detail. Our results showed that Dryocrassin ABBA induced HepG2 apoptosis via decreasing in the ratio of $\mathrm{Bcl}-2 / \mathrm{Bax}$ in mitochondria, and further induced triggering caspase cascades leading to apoptosis.

Apoptosis is a major mechanism in plant extractsinduced cancer cells death (Guy et al., 2000). Phenolic compounds are known to act as pro-apoptotic agent. For example, curcumin, a polyphenolic compound, could induce apoptosis by suppressing Bcl-2 expression and activating caspases- 7 and caspases-9 in mantle lymphoma cells (Quiney et al., 2006). Resveratrol, a phenolic compound, whose induction of apoptosis was associated with increased caspase activities, decreased Bcl-2 and Bcl-XL levels, and increased Bax levels in MCF-7 human breast cancer cells (Kong et al., 2009). Dryofragin is a phloroglucinol derivative extracted from Dryopteris fragrans (L.) Schott, containing two phenolic hydroxyls. Dryofragin induces human breast cancer MCF-7 cells apoptosis through ROS-mediated mitochondria-dependent pathway. Dryofragin inhibited Bcl-2 and induced Bax expression, which led to activation of caspases-3 in the cytosol, and further cleavage of poly ADP-ribose polymerase (PARP) in the nucleus, and then induced cell apoptosis (Zhang et al., 2012). The phenolic hydroxyls exhibited highly pro-apoptotic activity 
through the mitochondria-mediated pathway. Dryocrassin ABBA belongs to phloroglucinol derivatives containing many phenolic hydroxyls, which led us to hypothesize that Dryocrassin ABBA-induced apoptosis involves in mitochondria-mediated signaling. Our results showed that Dryocrassin ABBA effectively inhibited the proliferation of HepG2 cells in a dose-dependent manner. We also examined apoptotic marker in HepG2 cells exposed to different concentrations of Dryocrassin ABBA. After treatment, the cells showed increased percentages of apoptotic cells, which suggests that apoptosis was induced by Dryocrassin ABBA.

Apoptosis is a tightly regulated process under the control of several signaling pathways, such as caspase and mitochondrial pathways (Herr et al., 2001). Mitochondria-mediated apoptosis is precisely regulated by the Bcl-2 family proteins (Cory et al., 2002). The pro-survival protein $\mathrm{Bcl}-2$ in mitochondria, which prevents apoptosis by suppressing oxyradical-mediated membrane damage and stabilizing MMP (Kim et al., 2004). In contrast, the pro-apoptotic proteins Bax oligomerize in the mitochondrial outer membrane where it causes the release of apoptogenic factors through the outer membrane of mitochondria (Cory et al., 2002). We observed that Dryocrassin ABBA down regulated the expression of $\mathrm{Bcl}-2$, and up regulated the expression of Bax. Hence, the imbalance of Bax protein and Bcl-2 protein contributed to the $\mathrm{mPTP}$ opening and induction of apoptosis. These data indicate that Dryocrassin ABBA induced mitochondria-mediated apoptosis by regulating the expression of Bcl-2 family proteins. Caspases are necessary initiators and executioners of apoptosis. The two major apoptotic pathways are mitochondrial and death receptor-mediated (Fulda, 2009). The final step of these two mechanisms is caspase-3 activation and nuclear fragmentation. Activation of caspase- 3 plays a central role in the initiation of apoptosis, which requires the activation of initiator caspases, such as caspase-9, in response to pro-apoptotic signals (Nicholson et al., 1995). We found that Dryocrassin ABBA evoked caspase-3, caspase-7, and caspase-9 activation, suggesting that Dryocrassin ABBA-induced apoptosis indeed occurred via a caspasedependent pathway. Death receptor pathway involves in the ligation of the TNF/Fas-receptor with its ligand and the final step of this mechanism is caspase-3 activation (Timmer et al., 2002). According to the data, the gene level of Fas showed no change after the treatment. We all know that the tumor suppressor p53 is induced and activated in DNA damage mediated cell death (Thomas et al., 2000). Our date indicated that Dryocrassin ABBA increases the cellular levels of p53. We provided evidence that Dryocrassin ABBA induced a mitochondria-dependent apoptotic pathway via the modulation of Bax and Bcl2 expression, leading to activation of caspase-3 and caspase-7, involving p53 gene expression.

In summary, this study demonstrates that Dryocrassin ABBA induced apoptosis of HepG2 cells through caspase dependent mitochondrial pathway, involving in $\mathrm{Bcl} 2$ family protein expression. As in vivo experiment showed Dryocrassin ABBA hadeffective anti-tumor activities as shown in vitro experiment. Our results provide preliminary experimental evidences for supporting the possibility of Dryocrassin ABBA to be considered as a novel pharmacological treatment strategies in hepatocellular carcinoma.

\section{Acknowledgements}

This work was supported by the National Natural Science Foundation of China under Grant number 31070291; Training of scientific research project of National Natural Science Foundation of talents cultivation under Grant number J1210069.

\section{References}

Cory S, Adams JM (2002). The Bcl2 family: regulators of the cellular life-or-death switch. Nat Rev Cancer, 2, 647-56.

Fulda S (2009). Caspase-8 in cancer biology and therapy. Cancer Lett, 281, 128-33.

Fauzi AN, Norazmi MN, Yaacob NS (2011). Tualang honey induces apoptosis and disrupts the mitochondrial membrane potential of human breast and cervical cancer cell lines. Food Chem Toxicol, 49, 871-8.

Guo XZ (1992). Toxic herbal medicine dictionary. tianjin science and technology translation company.

Guy M, John AH (2000). Apoptosis and cancer chemotherapy. Cell Tissue Res, 301, 143-52.

Granado-Serrano AB, Martin MA, Bravo L, at al (2006). Quercetin induces apoptosis via caspase activation, regulation of Bcl-2, and inhibition of PI-3-kinase/Akt and ERK pathways in a human hepatoma cell line (HepG2). $J$ Nutr, 136, 2715-21.

Herr I, Debatin KM (2001). Cellular stress response and apoptosis in cancer therapy. Blood, 98, 2603-14.

Jiang S, Zu Y, Fu Y, et al (2008). Activation of the mitochondriadriven pathway of apoptosis in human PC-3 prostate cancer cells by a novel hydrophilic paclitaxel derivative, 7-xylosyl-10-deacetylpaclitaxel. Int J Oncol, 33, 103-11.

Kim YA, Choi BT, Lee YT, et al (2004). Resveratrol inhibits cell proliferation and induces apoptosis of human breast carcinoma MCF-7 cells. Oncol Rep, 11, 441-6.

Kuo CT, Hsu MJ, Chen BC, et al (2008). Denbinobin induces apoptosis in human lung adenocarcinoma cells via Akt inactivation, Bad activation, and mitochondrial dysfunction. Toxicol Lett, 177, 48-58.

Kong CS, Kim JA, Yoon NY, et al (2009). Induction of apoptosis by phloroglucinol derivative from Ecklonia Cava in MCF-7 human breast cancer cells. Food Chem Toxicol, 47, 1653-8.

Livak KJ, Schmittgen TD (2001). Analysis of relative gene expression data using real-time quantitative PCR and the $2^{-\Delta \Delta \mathrm{CT}}$ method. Methods, 25, 402-8.

Lau AT, Wang Y, Chiu JF (2008). Reactive oxygen species: current knowledge and applications in cancer research and therapeutic. J Cell Biochem, 104, 657-67.

Liu X, Zu YG, Fu YJ, at al (2009). Efferth, antimicrobial activity and cytotoxicity towards cancer cells of Melaleuca alternifolia (tea tree) oil. Eur Food Res Technol, 229, 247-53.

Li J, Bian WH, Wan J, et al (2014). Curdione inhibits proliferation of MCF-7 Cells by inducing apoptosis. Asian Pac J Cancer Prev, 15, 9997-10001

Nicholson DW, Ali A, Thornberry NA, et al (1995). Identification and inhibition of the ICE/CED-3 protease necessary for mammalian apoptosis. Nature, 376, 37-43.

Newman DJ, Cragg GM, Snader KM (2003). Natural products as sources of new drugs over the period 1981-2002. J Nat 
Prod, 66, 1022-37.

Nigam N, Bhui K, Prasad S, at al (2009). [6]-Gingerol induces reactive oxygen species regulated mitochondrial cell death pathway in human epidermoid carcinoma A431 cells. Chem Biol Interact, 181, 77-84.

Parkin DM (2001). Global cancer statistics in the year 2000. Lancet Oncol, 2, 533-43.

Perfettini JL, Reed JC, Israel N, et al (2002). Role of Bcl-2 family members in caspase-independent apoptosis during Chlamydia infection. Infect Immun, 70, 55-61.

Quiney C, Billard C, Salanoubat C, et al (2006). Hyperforin, a new lead compound against the progression of cancer and leukemia?. Leukemia, 20, 1519-25.

Roy MK, Thalang VN, Trakoontivakorn G, et al (2005). Mahanine, a carbazole alkaloid from Micromelum minutum, inhibits cell growth and induces apoptosis in U937 cells through a mitochondrial dependent pathway. $\mathrm{Br}$ $J$ Pharmacol, 145, 145-55.

Thomas A, Giesler T, White E (2000). P53 mediates Bcl-2 phosphorylation and apoptosis via activation of the $\mathrm{Cdc} 42 /$ JNK1 pathway. Oncogene, 19, 5259-69.

Timmer T, de Vries EG, de Jong S (2002). Fas receptor-mediated apoptosis: a clinical application? J Pathol, 196, 125-34.

Zhou YJ, Zhang SP, Liu CW, et al (2009). The protection of selenium on ROS mediated-apoptosis by mitochondria dysfunction in cadmium-induced LLCPK1 cells. Toxicol In Vitro, 23, 288-94.

Zhang Y,Luo M, Zu Y, et al (2012). Dryofragin, a phloroglucinol derivative, induces apoptosis in human breast cancer MCF-7 cells through ROS-mediated mitochondrial pathway. Chem Biol Interact, 199, 129-36. 